\title{
Aural temperature of the newborn infant
}

\author{
D. STRATTON
}

\author{
From the Department of Physiology, London Hospital Medical College
}

SUMMARY The aural, oesophageal, and rectal temperatures of 10 term infants were monitored during changes in environmental temperature. The aural temperature in normal infants was found to be consistently higher than at any other site. It is suggested that this finding is due to the local heating effect of brain metabolism and shows the important contribution to total body heat production made by the brain. The depressed aural temperature found in an infant with hydranencephaly is cited as supporting evidence and may indicate the potential of aural temperature measurement in the investigation of cerebral metabolism.

The ideal site for recording deep body temperature has been sought for many years. The mouth, oesophagus, and rectum can be unreliable, inconvenient, or potentially hazardous. These disadvantages apply equally to the sick neonate who, because of poor temperature control and dependence upon a neutral environmental temperature, demands an accurate, safe, and reliable method of monitoring deep body temperature. The external auditory meatus appears to offer the advantages of convenience and safety, but previous workers have shown that the temperature recorded from structures as deep as the tympanic membrane is influenced directly by environmental temperature ( Nadel and Horvath, 1970). Protection from the environment by servocontrolled heating around the ear (Keatinge and Sloan, 1973) gave promising results and inspired the development of a neonatal prototype of the Zero Gradient Aural Thermometer. The results and interpretations of investigations into the use of this device are here reported. Preliminary results have been reported (Cross and Stratton, 1974).

\section{Method}

The Zero Gradient Aural Thermometer (Muirhead Ltd.) is essentially two matched thermistors linked to a differential amplifier, the output of which is fed to a 3-watt heating pad. A temperature differential between the two thermistors, one of which is inserted half-way along the auditory canal and the other interposed between the pinna and the heating pad, triggers a current to the heating

Received 18 January 1977 pad until that temperature differential is abolished At this point there is no temperature gradient along the canal and the temperature recorded by the internal thermistor represents the deep body temperature at that site. The thermistor relationship, with the internal being the master and the external the slave, is constantly maintained and is unaffected by a rising or falling ambient temperature.

Thirty-five term infants were investigated in a metabolic chamber as described by Hill and Rahimtulla (1965) and modified by Hey (Hey and Katz, 1969). All infants were investigated with fully informed maternal consent and frequently in the presence of the mother. Only the 10 infants who completed the full series of investigations described below, in quiet natural sleep, were included in the study. Their mean weight was $2.99 \mathrm{~kg}$ (range $2.5-3.6 \mathrm{~kg}$ ) and the mean gestational age 40 weeks (range 37-42 weeks).

Temperature measurements were made using chromel/alumel thermocouple wires; the soldered ends were covered with a thin layer of epoxy resin and the remaining wire sheathed in a sealed Portex tube of $3 \mathrm{~mm}$ external diameter. Care was taken to standardize the positions of the thermocouples in each subject. After local anaesthesia of the nasal mucosa had been achieved with $5 \%$ lignocaine cream, an oesophageal lead was inserted via a nostril to a depth of $18 \mathrm{~cm}$. The end of a rectal lead was positioned $7 \mathrm{~cm}$ from the anus and a skin lead taped to the loin. The thermocouple leads were connected, via a thermostatically controlled cold junction at $45^{\circ} \mathrm{C}$, to a 12-channel Cambridge recorder. Calibration of the aural thermometer against an NPL standard thermometer indicated a linear response over the range $33-42^{\circ} \mathrm{C}$. All 
thermocouples were calibrated against the internal aural thermistor.

The infants were nursed prone in the metabolic chamber and observed closely throughout the investigation. 5 infants were initially placed in a neutral thermal environment at $33.8^{\circ} \mathrm{C}$ and 5 in a cool environment at $25 \cdot 8^{\circ} \mathrm{C}$. After a period to allow the infant to settle and his temperature to stabilize, oxygen consumption was recorded over 15-20 minutes. The environmental temperature was then lowered in the first group of infants and raised in the second. After a further period of at least 30 minutes for stabilization, oxygen consumption was again measured for 15-20 minutes. During the entire investigation, oesophageal, rectal, skin, and aural temperatures were recorded at 1-minute intervals. Environmental temperature within the chamber was deduced as the mean of temperatures recorded in the chamber air, on the chamber baffle plate, and from two sites on the chamber wall. Volumetric calibration of the oxygen consumption apparatus was performed after each investigation and the oxygen consumption calculated.

The relationship between blood temperature and aural temperature was clearly relevant to this investigation but because of ethical consideration it was possible to investigate only one infant, who was undergoing umbilical arterial catheterization as part of his standard intensive care. This infant weighed $2.94 \mathrm{~kg}$ and had a right pneumothorax. Catheterization of an umbilical artery was performed using a sterile FG3 catheter fitted with a thermistor (Cardio-Vascular Instruments, Type No. 3753). Aortic, aural, rectal, skin, and incubator temperatures were recorded at hourly intervals over a period of 16 hours. Oesophageal temperature was not recorded in this patient as it was felt that insertion of a nasal or oral lead, in addition to a nasogastric tube, would be unethical in an infant with respiratory distress. The thermocouples and the arterial catheter thermistor were calibrated against the internal aural thermistor as described above.

\section{Results}

The findings have been expressed graphically to show the relative changes in temperature between two sites. Fig. 1 shows the ability of this instrument to record changes in deep body temperature during environmental warming, the protected aural temperature appearing to respond more rapidly than either the oesophageal temperature or the rectal temperature. It is also apparent that after a latent period of 10 minutes the rise in oesophageal temperature bears a linear relationship to the rise in aural temperature but, perhaps more interestingly, that a fairly constant differential temperature of $0.15^{\circ} \mathrm{C}$ is maintained. A similarly shaped curve is obtained by plotting aural temperature against rectal temperature but the latent period is prolonged to 15 minutes and the temperature differential is increased to $0 \cdot 3^{\circ} \mathrm{C}$.

Figs 2 and 3 again show the aural-oesophageal temperature differential of $0.15^{\circ} \mathrm{C}$ in a neutral thermal environment, reducing to $0 \cdot 1^{\circ} \mathrm{C}$ with the application of cold stress. The inertia of a rectal temperature response is apparent from Fig. 3 with a latent period of about 20 minutes before a definite decrease is noted. Thereafter a linear relationship between aural and rectal temperatures is assumed, with the aural-rectal differential being reduced to $0.05^{\circ} \mathrm{C}$.

The mean oxygen consumption of the group of infants subjected to environmental warming was $8 \cdot 44 \mathrm{ml} / \mathrm{kg}$ per min (range 7.67-9.36 $\mathrm{ml} / \mathrm{kg} \mathrm{per} \mathrm{min}$ ) at $25.6^{\circ} \mathrm{C}$ falling to a mean value of $5.50 \mathrm{ml} / \mathrm{kg}$ per min (range $5 \cdot 19-5 \cdot 68 \mathrm{ml} / \mathrm{kg}$ per $\mathrm{min}$ ) at $33 \cdot 8^{\circ} \mathrm{C}$. The other group of infants, who were subjected to environmental cooling, gave similar results of $5 \cdot 31 \mathrm{ml} / \mathrm{kg}$ per min (range $4 \cdot 67-5 \cdot 77 \mathrm{ml} / \mathrm{kg}^{\circ}$ per

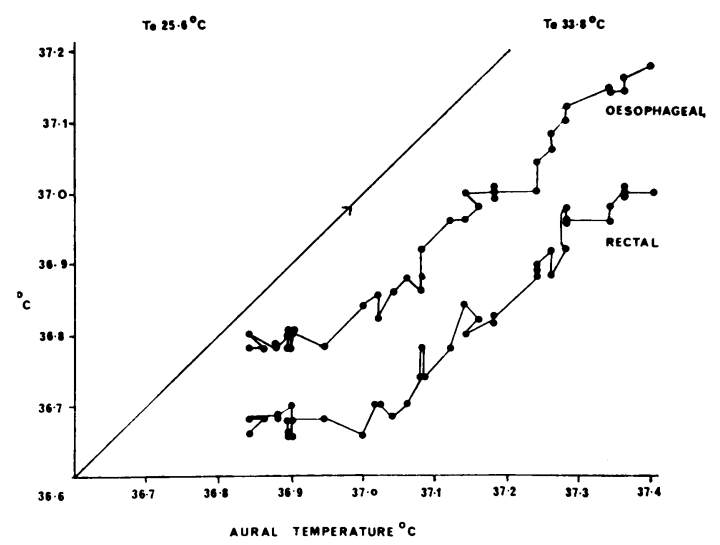

Figs. 1-3, 5 The points, linked to show the sequence of temperature change, represent the mean temperatures of 5 infants who were subjected to the same alteration of environmental temperature and are recorded at 1-minute intervals. Movement of points to the right of the line of identity indicates a relative increase in the temperature plotted on the abscissa (the aural temperature) over that plotted on the ordinate and vice versa. The direction of the environmental temperature change is shown by the arrow on the line of identity. On each graph, the points start with the first change of either temperature from the steady state.

Fig. 1 Relative changes in aural, rectal, and oesophageal temperature during environmental warming. 


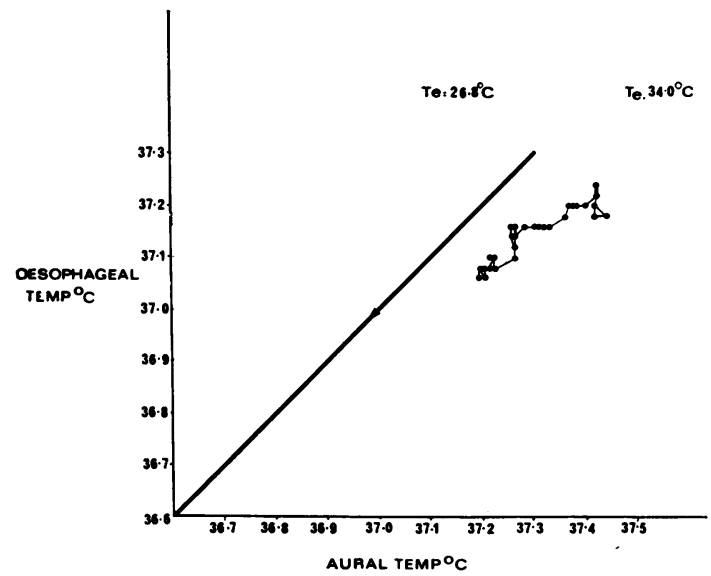

Fig. 2 Relative changes in aural and oesophageal temperatures during environmental warming.

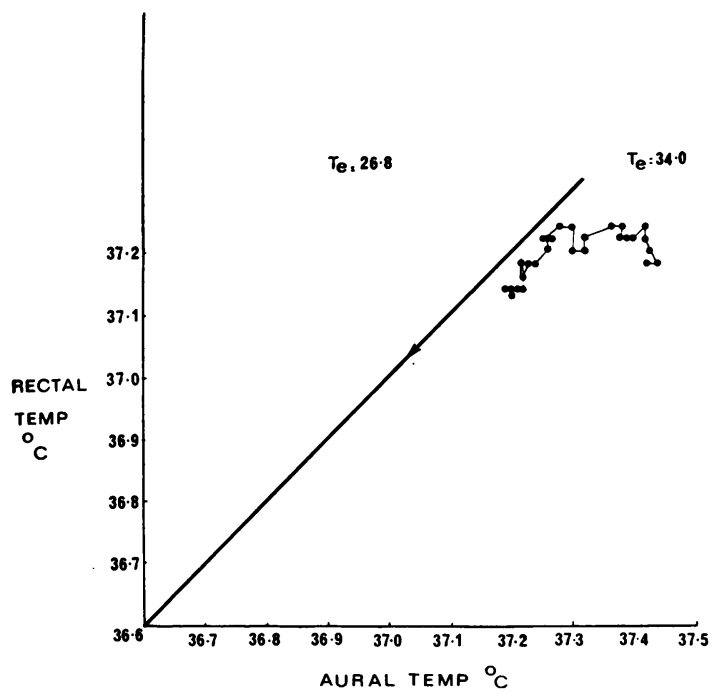

Fig. 3 Relative changes in aural and rectal temperatures during environmental cooling.

$\min$ ) at $34 \cdot 0^{\circ} \mathrm{C}$ and $8.43 \mathrm{ml} / \mathrm{kg}$ per min (range $7 \cdot 30-9 \cdot 47 \mathrm{ml} / \mathrm{kg}$ per $\mathrm{min}$ ) at $26 \cdot 8^{\circ} \mathrm{C}$.

Though the differential between aural and aortic temperature appeared to be highly variable in the infant investigated (Fig. 4), the aural temperature was consistently higher than both the aortic and rectal temperature.

\section{Discussion}

A review of available published reports suggests that the use of the external auditory canal for

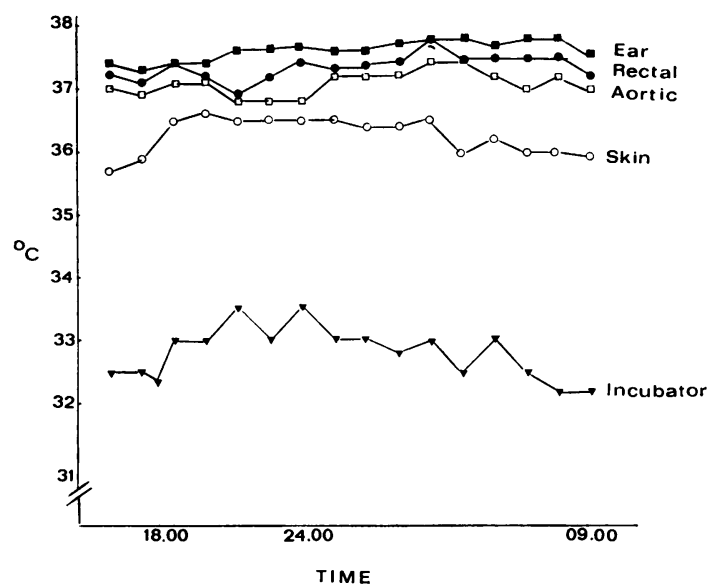

Fig. 4 Temperatures recorded from an infant with a right pneumothorax, showing the relationship of aural, rectal, and aortic temperatures.

temperature recording in the neonate has not until now been attempted. The initial aim of this investigation was to assess the ability of the neonatal version of this apparatus to monitor changes in deep body temperature in newborn infants in environmental temperatures that would normally be experienced in clinical practice. With familiarity, the insertion of the internal thermistor and fixation of the heating pad are not difficult, though care must be taken that the internal thermistor is against the wall of the auditory canal and that the heater is fixed securely.

The constant finding of a higher aural temperature than at any other site was unexpected. The arterial supply of the external auditory meatus is wholly derived from the external carotid artery and one would have expected the aural temperature to be equal to, or less than, the temperature of the carotid blood. The work of Eichna et al. (1951) has shown the similarity of low jugular venous temperature to femoral artery blood temperature in the adult and this would lead one to anticipate either no thermal gradient between the ear and the oesophagus or, more likely, a positive oesophagealaural temperature differential, the reverse of the current findings.

Injection of warm saline $\left(44^{\circ} \mathrm{C}\right)$ into the internal carotid artery in adults (Cooper et al., 1964) caused a prompt rise in the aural temperature measured without servo-heating, on the ipsilateral side. This was interpreted as reflux of the saline into the external carotid artery, even though carotid angiography performed immediately before the investigation showed filling of the internal carotid 
artery only. Moreover, a lesser though noticeable rise in aural temperature was recorded from the contralateral ear. Another interpretation of these findings is that the aural temperature is to some extent influenced by brain temperature. In the newborn infant the temperature gradient between the brain and the ear should be less than in the adult, due to the thinness of the cranial bones and to the poor ossification at this site in this age group. The provision of a servo-heater, by minimizing the influence of environmental temperature, should reduce this gradient still further.

It is likely that the high aural temperature is due to heating by local metabolism and the only organ of sufficient size at this site capable of providing such heat is the brain. Assuming that aural temperature is equivalent to brain temperature and that oesophageal temperature is equivalent to aortic and carotid temperature, one can deduce cerebral heat production by applying the Fick principle:

Heat produced $(\mathrm{cal} / \mathrm{min})=\left[\right.$ Brain temp $\left({ }^{\circ} \mathrm{C}\right)-$ Arterial temp $\left.\left({ }^{\circ} \mathrm{C}\right)\right] \times$ cerebral blood flow $(\mathrm{ml} / \mathrm{g}$ per $\min ) \times$ brain wt $(\mathrm{g})$.

When assessed at a neutral environmental temperature, the aural-oesophageal temperature differential was $0 \cdot 15^{\circ} \mathrm{C}$. Though no measurements of cerebral blood flow in healthy neonates have been reported, there are indications (Arnot et al., 1970) that the flow in this age group is as high as $100 \mathrm{ml} / 100 \mathrm{~g}$ brain per minute. The average brain weight of a normal $3 \mathrm{~kg}$ infant is reported to be $390 \mathrm{~g}$ (Potter, 1953). Substitution of these values in the above equation would suggest that the mean heat production of the brain of the newborn infants investigated was $58 \cdot 5 \mathrm{cal} / \mathrm{min}$. The total body heat production can be determined by measurement of oxygen consumption and is given by the formula:

Total heat produced $(\mathrm{cal} / \mathrm{min})=$ Oxygen consumption $(\mathrm{ml} / \mathrm{kg}$ per $\mathrm{min}) \times$ body wt $(\mathrm{kg}) \times$ caloric value for oxygen (cal).

The mean oxygen consumption in a neutral thermal environment was $5.5 \mathrm{ml} / \mathrm{kg}$ per min and the mean body weight $2.99 \mathrm{~kg}$. The caloric value for oxygen is $4.8 \mathrm{cal} / \mathrm{ml}$. Under these particular circumstances the total mean heat being produced by these infants was $79 \cdot 2 \mathrm{cal} / \mathrm{min}$. Comparison with the value obtained for cerebral heat production suggests that in a neutral thermal environment the brain of the newborn infant is responsible for $70 \%$ of the total body heat production. Furthermore, one can determine this same proportion under cold stress, when the aural-oesophageal temperature difference fell to $0 \cdot 1^{\circ} \mathrm{C}$ and the total oxygen consumption rose to $8.4 \mathrm{ml} / \mathrm{kg}$ per min, as $30 \%$ of the total heat production. Cerebral heat production may be relatively constant and unaffected by ambient temperature. An increase in total body heat production in response to cold stress could be achieved by the recruitment of additional somatic metabolic activity, such as thermogenesis from brown fat, leading to a reduction in the auralrectal temperature differential as seen in Fig. 3.

Although it may seem that a brain heat production of $70 \%$ of the total is a rather high proportion, using the same figures it appears that this represents $14 \cdot 3$ calories per $100 \mathrm{~g}$ of brain tissue per minute. This compares favourably with the heat production calculated from Folkow's findings (Folkow and Neil, 1971) that the adult brain consumes $45 \mathrm{ml}$ oxygen per minute. Assuming the adult brain to weigh $1400 \mathrm{~g}, 16.0$ calories per $100 \mathrm{~g}$ of brain tissue per minute are produced.

In the present state of knowledge these values obviously can only be estimates, but they may indicate the importance of the neonatal brain as a site of intense metabolism. This suggestion is not new, being first advanced by Kerpel-Fronius $e t$ al. (1961) who pointed out that though the adult brain was a mere $2 \%$ of body weight, its oxygen consumption was $18 \%$ of the total used by the whole body when assessed under resting conditions. The neonatal brain, however, represents $12 \%$ of body weight and extrapolation from adult values would clearly overestimate the neonatal cerebral oxygen consumption. At present it seems more appropriate to estimate oxygen consumption, albeit indirectly, from temperature measurements.

If the above assumptions are correct, the cerebral blood inflow is acting as a cooling system, removing heat produced by the brain. Working on this hypothesis, attempts were made to alter the cerebral blood flow in neonates using $2 \%$ carbon dioxide in $21 \%$ oxygen and $77 \%$ nitrogen breathed for 5 minutes, while aural and oesophageal temperatures were monitored. Similarly, $100 \%$ oxygen was breathed for the same length of time. An effect on the infants was noted by observing increasing respiratory movements in the former situation and the infant becoming pinker in the latter; no attempt was made to measure blood gases during the investigation. Neither procedure produced any constant response in terms of temperature differential or absolute measurements. This may have been due to the relative brevity of the procedure or to an incorrect assumption that the response of cerebral blood flow to hypercapnia and hyperoxygenation in the neonate is similar to that which occurs in the adult. 
Further support for some of the above assumptions was given by the results of the investigation of an 8-week-old infant, suspected of having hydranencephaly, who was referred for examination because of poor temperature control. No significant increase in oxygen consumption was recorded when cold stress was applied and the deep body temperature fell sharply soon after the environmental temperature was lowered. Thus, the infant was a 'poikilotherm' similar to the infants described by Cross et al. (1971), and at post mortem there proved to be only $115 \mathrm{~g}$ of macroscopical brain tissue. A reduction in the aural-oesophageal temperature differential from the normal was anticipated due to an obvious paucity of brain tissue as seen on transillumination. The reversal of the aural-oesophageal differential (Fig. 5)

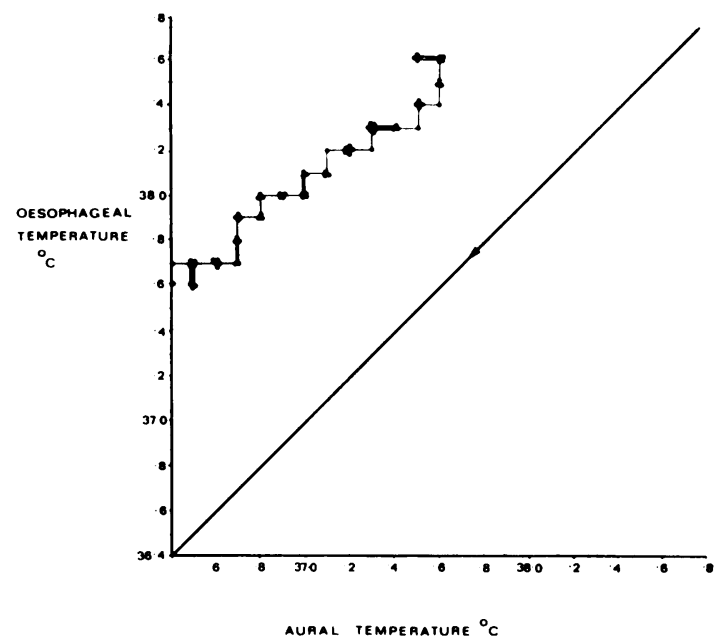

Fig. 5 Relative changes in aural and oesophageal temperatures in an infant aged 8 weeks with severe hydrocephalus during environmental cooling.

recorded in this infant in a neutral environmental temperature was maintained during cold stress, suggesting that the brain of the normal neonate is highly metabolically active and that the aural temperature can reflect brain temperature and hence activity with a suprising degree of accuracy. Further work is needed to determine whether this relatively simple measurement is sensitive enough to identify less gross cerebral malformations and to record the effect on aural temperature of metabolic disturbances such as hypoglycaemia or hypoxia due to birth injury.

My thanks are due to Professor K. W. Cross for his guidance; to Miss R. Warner, SRN for assistance with investigations and for illustrations; to the paediatric and obstetric staff of the London Hospital for permission to study infants in their care; and to the parents of the infants investigated. The British Oxygen Corporation gave a grant towards this work, which was supported by the Halley Stewart Trust.

\section{References}

Arnot, R. N., Class, H. I., Clarke, J. C., Davis, J. A., Schiff, D., and Picton-Warlow, C. G. (1970). Gasteiner Internationalen Symposion, Vol. IX, p. 60. Gasteiner, Austria.

Cooper, K. E., Cranston, W. I., and Snell, E. S. (1964). Temperature in the external auditory meatus as an index of central temperature changes. Journal of Applied Physiology, 19, 1032-1035.

Cross, K. W., and Stratton, D. (1974). Aural temperature of the newborn infant. Lancet, 2, 1179-1180.

Cross, K. W., Hey, E. N., Kennaird, D. L., Lewis, S. R., and Urich, H. (1971). Lack of temperature control in infants with abnormalities of the central nervous system. Archives of Disease in Childhood, 46, 437-443.

Eichna, L. W., Berger, A. R., Rader, B., and Becker, W. H. (1951). Comparison of intracardiac and intravascular temperatures with rectal temperatures in man. Journal of Clinical Investigation, 30, 353-359.

Folkow, B., and Neil, E. (1971). Circulation, p. 12. Oxford University Press, London.

Hey, E. N., and Katz, G. (1969). Evaporative water loss in the newborn baby. Journal of Physiology, 200, 605-619.

Hill, J. R., and Rahimtulla, K. A. (1965). Heat balance and the metabolic rate of newborn babies in relation to environmental temperature; and the effect of age and weight on basal metabolic rate. Journal of Physiology, 180, 239265.

Keatinge, W. R., and Sloan, R. E. G. (1973). Measurement of deep body temperature from external auditory canal with servo-controlled heating around the ear. Journal of Physiology, 234, 8-9P.

Kerpel-Fronius, E., Varga, F., and Mestyan, G. (1961). Clinical aspects of stability. Somatic Stability in the Newly Born, p. 324. Ed. by G. W. Wolstenholme and M. O'Connor. Ciba Foundation symposium. Churchill, London.

Nadel, E. R., and Horvath, S. M. (1970). Comparison of tympanic membrane temperature and deep body temperatures in man. Life Sciences, 9, 869-875.

Potter, E. L. (1953). Pathology of the Foetus and the Newborn, p. 13. Year Book Publishers, Chicago.

Correspondence to Dr. D. Stratton, Department of Child Health, Royal Hospital for Sick Children, St. Michael's Hill, Bristol 2. 